\title{
A new database of mitochondrial DNA hypervariable regions I and II sequences from 162 Japanese individuals
}

Received: 9 September 2004 / Accepted: 5 October 2004 / Published online: 19 January 2005

(C) Springer-Verlag 2005

\section{Int J Legal Med (2001) 116:68-73}

Data transcriptional errors have been identified in two sequences from a Japanese mtDNA database that we published in this article. The electronic supplementary table of that paper lists sequences JP059 and JP061 as having an A at position 113. This is incorrect. In both cases, the position should have been listed as 103 , with an A transition. A corrected supplementary table is now available (http://dx. doi.org/10.1007/s00414-004-0499-3), and GenBank sequences with accession numbers AF501144 and AF50 1214 have also been corrected. We thank Claudio Bravi for alerting us to this error.

The online version of the original article can be found at http://dx. doi.org/10.1007/s004140100211

Electronic Supplementary Material Supplementary material is available in the online version of this article at http://dx.doi. org/10.1007/s00414-004-0499-3

K. Imaizumi

National Research Institute of Police Science,

6-3-1, Kashiwanoha,

Kashiwa, Chiba, 277-0882, Japan

T. J. Parsons $(\bowtie)$

Armed Forces DNA Identification Laboratory,

1413 Research Blvd.,

Rockville, MD 20850, USA

e-mail: parsons@afip.osd.mil

Tel.: 1-301-3190268

Fax: 1-301-2955932 